\title{
O VALOR LEGAL DE ARQUIVOS ELETROONICOS DE IMAGEM EM RADIOLOGIA ODONTOLÓGICA
}

\author{
Camila Castelo Branco Véras Pinheiro*, Thaiane Rodrigues Aguiar**, Jacqueline Gurjão Rios*** \\ Autora correspondente: Camila Castelo Branco Véras Pinheiro: E-mail: camilacbveras@hotmail.com \\ * Mestranda em Gestão e Tecnoçogia Aplicadas à Educação- GESTEC/UNEB, Especialista em Programa de Saúde da \\ Família pela UNIJORGE e em Radiologia e Imaginologia odontológica pela Associação Brasileira de Odontologia-ABO. \\ ** Doutora e Mestre em Clínica Odontológica/Dentística pela Faculdade de Odontologia de Piracicaba/Universidade \\ Estadual de Campinas (UNICAMP).Professora da Pós-graduação EAD Unijorge e da Faculdade Regional da Bahia (UNIRB). \\ *** Mestre em Odontologia pela Universidade Federal da Bahia (UFBA). Professora assistente do Curso de Tecnologia \\ em Radiologia do Instituto Federal de Educação, Ciência e Tecnologia da Bahia e professora assistente do Curso de \\ Odontologia da Escola Bahiana de Medicina e Saúde Pública.
}

\begin{abstract}
Resumo
Introdução e objetivo: Este estudo buscou investigar produções científicas a respeito do valor legal de arquivos eletrônicos de imagem em radiologia odontológica. Materiais e Métodos: Foi realizada uma revisão da literatura, a partir de busca em periódicos especializados utilizando as palavras-chave: odontologia legal, radiografia dentária digital e responsabilidade civil, no banco de dados da BIREME. Ao final da busca foram encontrados 23 artigos (18 nacionais e 05 internacionais) publicados no período entre 2000 e 2014. O conteúdo dos artigos foi analisado e discutido, segundo o objetivo desta revisão de literatura. Resultados e Discussão: Os resultados encontrados indicam que ao longo do período estudado, o uso de arquivos eletrônicos de imagem em radiologia odontológica funciona como aliado importante no diagnóstico, tratamento e prognóstico das diversas patologias do sistema estomatognático. Os arquivos digitais têm sua validade jurídica questionada já que são passíveis de manipulação, a certificação digital é o que garante a autenticidade e a integridade desses documentos juridicamente. Conclusões: Os arquivos eletrônicos de imagem promovem benefícios na área odontológica como melhores resultados terapêuticos, já que auxiliam num diagnótico mais preciso. Esses arquivos necessitam da certificação digital vinculadas a ICP-Brasil (Public Key Infrastructure) para assegurar o seu valor legal garantido-o como meio de prova processual. São necessários novos estudos a respeito da validade jurídica dos arquivos eletrônicos de imagem voltados para a radiologia odontológica.
\end{abstract}

Palavras-chave: Odontologia Legal; Radiografia Dentária Digital; Responsabilidade Civil. 


\title{
THE LEGAL VALUE OF ELECTRONIC IMAGE FILES IN DENTAL RADIOLOGY
}

\begin{abstract}
Introduction and objective: This study aimed to investigate scientific productions about the legal value of electronic image files in dental radiology. Materials and Methods: A literature review was conducted, from search in professional journals using the key words: forensic dentistry, dental digital radiography and liability in the BIREME database. At the end of search found 23 articles ( 18 national and o5 international) published between 2000 and 2014. The content of the articles was analyzed and discussed, according to the purpose of this review. Results and Discussion: The results indicate that over the study period, the use of electronic image files in dental radiology functions as important allies in the diagnosis, treatment and prognosis of various pathologies of the stomatognathic system. Digital files have their legal validity questioned as they are subject to manipulation, digital certification is what ensures the authenticity and integrity of documents legally. Conclusions: The image of electronic files promote benefits in the dental field as better therapeutic results, since that aid in more precise opportune diagnosis. These files require the digital certification linked to ICP-Brazil to ensure their guaranteed-legal value as a procedural evidence. Further research concerning the legal validity of electronic image files focused on dental radiology.

Keywords: Forensic Dentistry; Dental Radiography Digital; Civil Responsibility.
\end{abstract}

\section{INTRODUÇÃO}

A facilidade de acesso aos computadores e às diversas inovações tecnológicas na área da saúde tem possibilitado aos cirurgiões-dentistas a incorporação de novas condutas e ferramentas para informatizar seus consultórios. Os profissionais de saúde têm optado cada vez mais pelo uso de arquivos eletrônicos e imagens digitais devido às inúmeras vantagens como a rapidez no processo de aquisição e manipulação de imagens, a melhoria nos processos de gerenciamento e arquivamento de dados, a agilidade na busca por fichas clínicas de pacientes e a redução dos níveis de exposição à radiação $X .^{(1,2)}$

As radiografias odontológicas são consideradas como exames complementares de grande importância devido à enorme quantidade de informações que podem auxiliar nas ques- tões jurídico-legais em casos de alegação de "erro odontológico" e em casos de identificação odontolegal.(3,4) Porém, os arquivos eletrônicos e as imagens digitais têm seu valor legal questionado devido à facilidade com que podem ser manipulados e apresentar, em alguns casos, o conteúdo de suas informações alteradas. (1) Segundo Blum 2002,(5) para que se obtenha a validade jurídica inquestionável é necessária a autenticação utilizando um certificado digital emitido por entidade credenciada a Infra-Estrutura de Chaves Públicas Brasileira - ICP-Brasil, disciplinando a questão da presunção de integridade, autenticidade e validade dos documentos eletrônicos.

Outra possibilidade para evitar o uso de imagens alteradas, seria a disponibilização por parte dos fabricantes de um software específico ou em 
formato de imagem padrão, assim como ocorre na área médica, onde vem sendo utilizado o formato Digital Imagingand Communications in Medicine (DICOM) que não permite qualquer tipo de alteração. ${ }^{(6)}$

Em vista disso, o presente trabalho detém relevância, pois busca esclarecer aspectos importantes sobre a legalidade dos arquivos eletrônicos de imagem em radiologia odontológica. Nessa perspectiva, o objetivo deste estudo foi investigar as produções científicas sobre o valor legal dos arquivos eletrônicos de imagem em radiologia odontológica.

\section{METODOLOGIA}

Foi realizada uma revisão da literatura, tendo como principal fonte a base de dados Bireme. Os critérios de inclusão definidos para a seleção dos artigos foram: todas as categorias de artigo (original, revisão de literatura, reflexão, atualização, relato de experiência, dissertações, teses etc.), artigos publicados em português e inglês; artigos disponíveis na íntegra que retratassem a temática em estudo, publicados entre os anos de 2000 e 2014, utilizando-se as palavras-chave: odontologia legal, radiografia dentária digital e responsabilidade civil. Foram excluídos os materiais repetidos e aqueles que não atenderam os critérios de inclusão supramencionados. Desta maneira, após os critérios de refinamento de busca estabelecidos, foram incluídos no estudo 23 artigos (18 nacionais e 05 internacionais), de um total de 43 encontrados. A pergunta norteadora para a construção desta revisão de literatura foi: Quais as maneiras de garantir validade jurídica dos arquivos eletrônicos de imagem em radiologia odontológica? O conteúdo dos artigos foi analisado e discutido segundo o objetivo da revisão de literatura.

\section{REVISÃO DE LITERATURA}

\section{ARQUIVOS ANALÓGICOS DE IMAGEM X ARQUIVOS DIGITAIS DE IMAGEM}

Desde sua descoberta, por Wilhelm Conrad Röntgen, em 1895, os raios X vêm sendo utilizados, com distintas aplicações em diversas áreas da ciência. O filme radiográfico intrabucal convencional e os equipamentos analógicos vêm sendo amplamente utilizados, mas com o desenvolvimento da computação, vislumbrou-se a possibilidade de manipular as imagens radiográficas com o uso de computadores e, para isso, seria necessário obter imagens digitais. (7) Assim, novas formas de diagnóstico por imagem têm buscado substituir as radiografias convencionais, tornando cada vez mais popular o uso desta tecnologia. ${ }^{(8)}$

Os métodos para a formação de imagens radiográficas digitais são classificados em três tipos: o indireto, semi-direto e o direto. No método indireto (também conhecido como híbrido), a imagem digital é obtida a partir da digitalização, por escâner ou câmera fotográfica digital, por exemplo, de uma imagem obtida, originalmente, em filme. No método semi-direto, a imagem é capturada por uma placa de armazenamento de fósforo - Phosphor Stimulable Plate (PSP) -, mas não apresenta um cabo de conexão ao computador. Neste método é necessário um sistema de leitura conectado a um computador para transformar o sinal recebido pela placa óptica em sinal digital, após o escaneamento o receptor é dessensibilizado e pode ser reutilizado. Esses dois métodos são denominados radiografias computadorizadas enquanto o método direto é apresentado como a radiografia digital propriamente dita. Nesse último, a captura da imagem é realizada diretamente por um sensor eletrônico de carga acoplada - Charge CoupleDevice (CCD) - ou por um sensor baseado na tecnologia Complementary Metal Oxide Semiconductor (CMOS). (9) Assim, no sistema digital, o filme e o processamento radiográfico são substituídos por um sensor eletrônico e pelo computador. ${ }^{(10)}$ 
Os sistemas digitais de imagens oferecem inúmeras vantagens sobre os sistemas radiográficos convencionais como: minimizar o tempo de exposição aos raios $X$, armazenamento das imagens em mídias eletrônicas, permitem a manipulação e ajuste das imagens no monitor do computador para aprimorar sua interpretação e facilitar o diagnóstico, as imagens são projetadas no monitor do computador com 256 tonalidades de cinza, enquanto que, a olho nu, na radiografia convencional, é possível diferenciar apenas 25 tons.

Como desvantagens dos sistemas digitais podem-se citar: alto custo, necessidade de treinamento do profissional na área de informática, necessidade de grande capacidade de memória dos computadores, podem ser facilmente manipuladas por meio de programas de edição de imagem com o intuito de alterar ou omitir resultados. ${ }^{(11)}$

A fotografia é outro importante avanço tecnológico a favor da odontologia já que auxilia no diagnóstico, planejamento, discussão do caso clínico e acompanhamento da evolução do tratamento. A fotografia digital é imediatamente visualizada e caso a imagem não tenha alcançado o padrão ideal, imediatamente se faz um novo registro, sem nenhum custo adicional ao paciente ou ao profissional. Somam-se às vantagens já citadas, a possibilidade de manipulação imediata das imagens digitais. ${ }^{(12)}$ Estas, ao contrário das convencionais, podem ser facilmente otimizadas por programas específicos para edição de imagens. ${ }^{(13)}$ A digitalização dos modelos de gesso através das fotografias digitais é mais uma vantagem dessa técnica. $O \mathrm{ar}$ mazenamento dos modelos reduz riscos de danos ou perda de informação, por tempo indeterminado no HD de um computador ou em outro dispositivo de armazenamento. ${ }^{(14,15,16)}$

\section{MANIPULAÇÃO DE ARQUIVOS ELETRÔNICOS DE IMAGEM X VALIDADE JURÍDICA}

A possibilidade de manipulação dos arquivos digitais (radiografias, fotografias e modelos digi- talizados) auxilia na interpretação do diagnóstico, entretanto confere certo potencial fraudulento aos arquivos, se utilizado com intenções ilícitas. Desta forma, a credibilidade das imagens e arquivos digitais é muito discutida, o que determina questionamentos sobre sua validade jurídica. Para garantir a autenticidade e veracidade dos arquivos digitais e que estes tenham sua validade jurídica inquestionável é necessário a autenticação através da certificação digital.

Esta certificação é realizada pelos certificados digitais, que são meios eletrônicos de autenticação e verificação da identidade digital das partes envolvidas numa transação. Essa tecnologia possibilita o reconhecimento da assinatura das pessoas que trocam informações ou realizam transações digitais com segurança, sigilo e autenticidade. ${ }^{\left({ }^{(7)} \mathrm{A}\right.} \mathrm{Acr}$ tificação digital garante, além do sigilo e privacidade de documentos, a segurança dos mesmos, impedindo que estes sejam adulterados. O desenvolvimento dessa tecnologia vem transpor as relações de confiança que já existem no mundo físico para o ambiente digital. ${ }^{(18)}$

Assim, o governo brasileiro, pela Medida Provisória (MP) 2200-2, publicada em 24 de agosto de 2001, instituiu a Infra-estrutura de Chaves Públicas Brasileiras (ICP- Brasil), com poderes para formar no Brasil a cadeia de certificação digital, destinada a garantir a autenticidade, integridade e validade jurídica dos documentos eletrônicos, bem como a realização de transações eletrônicas seguras. ${ }^{(19)}$

A emissão de certificados é obrigatoriamente presencial, o solicitante preenche um cadastro e em seguida é gerado um par de chaves criptográficas que será armazenado em dispositivos protegidos com uma senha pessoal tais como CDs, token ou smart card. O token é um hardware criptográfico, com dimensões semelhantes à de uma chave doméstica e com dispositivo para ser acoplado na porta USB. O smartcard é um cartão criptográfico, com as mesmas dimensões de um cartão de crédito bancário. Uma vez gerada as chaves criptográficas e armazenadas no dispositivo escolhido, as chaves estão totalmente protegidas, não sendo 
possível exportá-las para outra mídia, nem retirá-las da mídia em que estão; assim, não são expostas ao risco de roubo ou violação. ${ }^{(20)}$

O certificado digital é considerado válido a partir do momento de sua emissão. Com ele, o indivíduo poderá assinar todos os documentos emitidos na forma eletrônica. Através de um software para assinatura de documentos (alguns distribuídos gratuitamente na internet $-X$ Sign, por exemplo) poderá selecionar qualquer arquivo, não importando seu formato (texto, imagem ou vídeo) e inserir sua assinatura. Quando um arquivo eletrônico é assinado digitalmente, este não poderá ser alterado, de forma que se isso ocorrer será indicado que houve violação de seu conteúdo após a assinatura. Assim, um documento eletrônico assinado tem a garantia de integridade (pois a informação não pode ser modificada), de não repúdio (a origem não pode ser negada) além da garantia da autenticação (pois identifica a pessoa de quem a informação procedeu).(1)

Outra possibilidade para garantir a confiabilidade dos documentos digitais, seria por meio de softwares específicos que evitam a manipulação das imagens, através desses softwares essas imagens estão sendo aceitas nos Estados Unidos como prova processual. $\mathrm{Na}$ área médica, o software utilizado tem formato DICOM, sendo usado nos tomógrafos computadorizados e imagens por ressonância magnética, e não permite qualquer tipo de alteração da imagem. Essas imagens estão sendo aceitas nos Estados Unidos como prova processual, entretanto, o custo da implementação deste sistema é considerado elevado. ${ }^{(6)}$

Entretanto, o custo da implementação deste sistema é considerado elevado. ${ }^{(6)}$ Caso haja documentos que originalmente não estejam no formato eletrônico, estes podem ser digitalizados e autenticados quando apresentados e conferidos por autoridade competente (Autoridade de Registro ou Cartório credenciado), que ateste a autenticidade com o original, dispensando, dessa maneira, o suporte físico, e assegurando validade jurídica para o documento eletrônico. ${ }^{(1)}$

\section{RESULTADOS E DISCUSSÃO}

Os estudos foram analisados, a partir de leitura criteriosa, voltada aos pontos estabelecidos para esta revisão. Os autores foram unânimes em afirmar os impactos positivos do uso de arquivos eletrônicos de imagem como as radiografias e fotografias digitais como também os modelos de gesso digitalizados no que tangem a um diagnóstico mais preciso logo, um tratamento mais eficaz. Contudo a manipulação desses arquivos é de fácil execução e de difícil identificação. Com o objetivo de avaliar a capacidade dos cirurgiões dentistas em identificar manipulações em imagens radiográficas digitais, Guedes et al., em 2007, ${ }^{(6)}$ apresentaram imagens manipuladas para duzentos avaliadores de diversas especialidades e acadêmicos, como resultado, apenas $14,13 \%$ das imagens com manipulação foi corretamente interpretado pelos avaliadores, sendo que não se observou diferença estatisticamente significante entre os examinadores com diferentes especialidades, incluindo especialistas em radiologia. Entretanto, observou-se diferenças significativas em relação aos acadêmicos e especialistas. Diante destes resultados concluíram que as imagens radiográficas digitais manipuladas são difíceis de serem identificadas pelos cirurgiões dentistas, inclusive pelos radiologistas.

A autenticidade jurídica dos arquivos eletrônicos de imagem se dá pela certificação digital porém, Eid et al. $2007^{(7)}$ num estudo para avaliar o conhecimento e utilização da certificação digital em clínicas de radiologia odontológica particulares de todo - Brasil, observaram que os arquivos eletrônicos são bastante utilizados, porém a certificação digital é pouco empregada para assiná-los por falta de conhecimento sobre o uso da certificação. Questionou-se o conhecimento dos entrevistados sobre a MP 2200-2 de 24 de agosto de 2001 nas cinco regiões brasileiras, $68,9 \%$ dos voluntários da região Sudeste conhecem o regimento da MP 2200-2; assim também $60,0 \%$ dos entrevistados da região Sul; $57,1 \%$ da região Centro-Oeste; $58,3 \%$ da região Norte e $64,3 \%$ da região Nordeste. Em relação aos que afirmaram possuir certificados digitais, $25,0 \%$ 
dos entrevistados da região Norte possuíam certificado digital, na região Sudeste $13,5 \%$, seguidos de $13,3 \%$ na região Sul e 7,1\% nas regiões Nordeste e Centro-Oeste.

Verificando-se os aspectos de legalidade, conhecimento e utilização dos documentos digitais em odontologia pelos cirurgiões-dentistas do Paraná, Lolli et al. 2011, ${ }^{(21)}$ observaram que a maioria dos entrevistados já ouviu falar e conhece alguns documentos digitais mas, desconhecem a certificação digital e nunca ouviram falar em chaves públicas brasileiras.

Assim, destaca-se a necessidade de difundir a certificação digital entre os dentistas já que a maioria não fazem uso por falta de conhecimento.

Já o estudo realizado por Yarid et al. $2011^{(22)}$ buscou investigar junto aos magistrados de Varas Cíveis Brasileiras, estes foram questionados via e-mail: "Muito se tem comentado, com prós e contras, a utilização de radiografias digitalizadas em detrimento da radiografia convencional. Qual é a percepção do magistrado quanto aos meios de prova digitalizados?". Após análise das respostas concluiu-se que os documentos digitalizados podem ser utilizados, não havendo vedação legal de seu aproveitamento, desde que, possa ser constatado, inclusive por perícia, se necessário, que são arquivos que representam com exatidão o fato, sem falsificações ou outras formas de macular a verdade. Para os Magistrados todo meio de prova que fornece subsídios importantes para o deslinde do caso é bem vindo. Contudo, se a parte, contra quem for exibida a prova, impugnar a exatidão desta, poderá ficar sujeita a exame pericial. ${ }^{(22)}$

A discussão e esclarecimento de dúvidas sobre a manuseio de documentos eletrônicos é de suma importância já que a manipulação com finalidade ilícita é crime, colocando à prova os valores da ética profissional. Assim, a idoneidade do cirurgião-dentista pode ser discutida a partir do momento em que a autenticidade do documento digital seja questionada, podendo o cirurgião-dentista responder por um processo judicial. ${ }^{(23)}$

\section{CONCLUSÕES}

Com base na literatura pesquisada e, a partir da contextualização voltada para a legalidade dos arquivos eletrônicos de imagem em radiologia odontológica é possível concluir que: os arquivos eletrônicos de imagem são de suma importância na odontologia otimizando o trabalho do cirurgião-dentista e vantajosos também para os pacientes, pois permitem uma maior acurácia no diagnóstico.

Os documentos em forma eletrônica podem ser utilizados como prova em processos judiciais, desde que estejam com a certificação digital dos mesmos vinculada à ICP-Brasil, pois esta garante a autenticidade, integridade, a confidencialidade e o não repúdio dos documentos digitais.

A realização de novos estudos sobre certificação digital para validação jurídica dos arquivos eletrônicos de imagem é necessária para que sua aplicação seja efetiva e eficaz entre os cirurgiões-dentistas.

\section{REFERÊNCIAS}

1. Pereira CB. Confiabilidade dos documentos digitais. [acesso em 2014 maio. 24]. Disponível em: http://www.jornaldosite.com.br/arquivo/ anteriores/bidegain/artbidegain67.htm.

2. Eid VMC. Avaliação do conhecimento e utilização da certificação digital em clínicas de radiologia odontológica [dissertação]. São Paulo: Universidade Estadual de Campinas, 2007.

3. Dia R., et al. Transposición dental y sus implicacioneseticas y legais. Rev. ADM. 2005;5: 185-190.

4. Silva RF et al. La importância de la documentación odontológica em la identificación humana. Acta odontol. 2005;2:6774.

5. Blum R. A certificação digital e o direito. [acesso em 2014 abr. 2O]. Disponível em http:// opiceblum.com.br

6. Guedes F., et al. O cirurgião dentista é capaz de identificar manipulações em imagens 
radiográficas digitais? Arq. bras. odontol. 2007;2:95-100.

7. Eid N. Avaliação do conhecimento e utilização da certificação digital em clínicas de radiologia odontológica. Revista da ABRO. 2007;1:jan./jun.

8. Sales M, Costa LJ, Neto JBSN. Controvérsias em radiologia digital. Rev. bras. patol. oral. 2002;22:232-235.

9. Pinto R, Rubira C. Radiografia digital. Rev. ciênc. odontol. 2000;3:47-52.

10. Gonçalves P, Dotta E, Serra M. Imaginologia na odontologia e aspectos legais. RGO. 2011;59:8995.

11. Whaites E. Princípios da radiologia odontológica. Porto Alegre: Artmed; 2003.

12. Bastos GK. A fotografia digital na ortodontia. São Paulo: Santos; 2004.

13. Machado A, Souki B. Simplificando a obtenção e a utilização de imagens digitais-scanners e câmeras digitais. Rev. dent. press ortodon. ortopedi. facial. 2004;4:133-156.

14. Redmond RW. Digital Models: A New Diagnostic Tool. J. clin. orthod. 2001;35(6):21-24.

15. Stewart M. Dental Models in 3D. Orthodontic Products. [acesso em 2014 maio 24]. Disponível em: http://www.orthocad.com/services/articles/ Stewart_Feb._2001.PDF
16. Santoro M, Galkin S, Teredesai M, Nicolay OF, Cangialosi TJ. Comparison of measurements made on digital and plaster models. Am. j. orthod. dentofacial orthop. 2003;1:101-105.

17. Eid, N. Certificação digital na odontologia. Jornal Ortodontia. 2004;5:76.

18. Pereira C, Eid N. Validação jurídica dos documentos digitais. Jornal da ABRO. 2004; 5:14.

19. Brasil. Presidência da República. Casa Civil. Subchefia para assuntos jurídicos. Medida Provisória 2200-2. [acesso em 2014 abr. 15]. Disponível em: http://www.planalto.gov.br/ civil_O3/MPV//22OO-2.htm

2O. Soares M. Arquivos digitais na odontologia. Rev. Assoc. Paul. Cir. Dent. 2006;4:281-284.

21. Lolli LF et al. Documentos digitais em odontologia - aspectos de legalidade, conhecimento e utilização por cirurgiõesdentistas. Uningá Review. 2011;2:112-21.

22. Yarid S. Percepção do magistrado brasileiro quanto às provas digitalizadas. RGO. 2011;2:17983.

23. Soares $M G$ et al. Verdades e mentiras sobre a legalidade da radiografia digital na Odontologia. Rev. bras. odont. 2004;1:22-24. 